Глава 2. Интродукция и сортоизучение

\title{
RESISTANCE OF CUT SHOOTS OF EVERGREEN GREENHOUSE SPECIES
}

\author{
Kabusheva I. N., Sak N. L., Katkovskaya N. S., Sandrozd Yu. I. \\ The State Scientific Institution \\ "Central Botanical Garden of Belarus National Science Academy", \\ c. Minsk, Belarus, e-mail: kabusheva_hbc@mail.ru
}

The paper presents research results about the longevity of storing cut shoots from 21 evergreen tropical and subtropical woody greenhouse species belonging to 17 families. It describes some morphological features of shoots and leaves which are important for characterizing their ornamental qualities as cut greenery. It was shown that the studied species are characterized by medium and high resistance of cut shoots (5-28 days and more) and are promising for expanding staffage greenery assortment both on the domestic and foreign floristic market.

Key words: resistance of cut plants, staffage greenery, evergreen plants, greenhouse plants, morphological features of shoots.

\section{КОЛЛЕКЦИЯ РОДА $A N E M O N E$ L. В УСЛОВИЯХ ВЛАЖНЫХ СУБТРОПИКОВ}

Козина В. В., Козина С. В.

\author{
Федеральное государственное бюджетное научное учреждение \\ «Всероссийский научно-исследовательский институт ияветоводства и субтропических культур», \\ 2. Сочи, Россия, e-mail: tsvetovodstvo@vniisubtrop.ru
}

Род Anemone L. относится к семейству лютиковых (Ranunculaceae L.). На коллекционном участке ФГБНУ ВНИИЦиСК имеется три вида - Anemone coronaria, Anemone blanda и Anemone hupehensis. На текущее время в коллекции института находятся шестнадцать сортов анемоны корончатой, два сорта анемоны хубэйской - 'Рamina' и 'Max Vogel', и белая гибридная форма, а также два сорта анемоны нежной - 'Rosea' и 'White Splendor'. Продолжительность цветения сортов A. coronaria - 51-68 дней, A. blanda до 45, A. hupehensis - 70-90 дней (10-12 недель). Средний диаметр цветка отечественных сортов $A$. coronaria составляет 8,5 см, средняя высота цветоноса - 34,6 см, тогда как средний диаметр цветка зарубежных сортов $-6,5$ см, а средняя высота цветоноса $-24,6$ см. Диаметр цветка сорта 'White Splendor' - 5,0 см, а высота цветоносов - 15,5 см. На одном растении A. hupehensis обычно имеется от семи до двенадцати цветоносов, высота их достигает 120 см. Одновременно цветущих цветков на одном цветоноce - 2-3 шт. Диаметр цветков A. hupehensis - 4-7 см.

Ключевые слова: Aneтопе, коллекция, род, сорт, условия выращивания. 
Anemone L. относится к семейству лютиковых (Ranunculaceae L.), включает в себя около 85 видов. Это многолетние травянистые растения, которые являются эфемероидами - геофитами, характеризующимися коротким периодом развития и приспособленностью к жизни в условиях умеренного увлажнения.

В коллекции института (ФГБНУ ВНИИЦиСК) находятся три вида анемона корончатая (Anemone coronaria L.), анемона нежная (Anemone blanda Schott \& Kotschy) и анемона хубейская (Anemone hupehensis (E'Lemoine) E'Lemoine).

В результате окультуривания анемоны корончатой (Anemone coronaria) в Европе были созданы и поддерживаются ряд широко известных сортов, которые на протяжении многих лет пользуются популярностью, как у профессионалов, так и у садоводов-любителей. Большое распространение, как промышленная культура, анемона получила в Италии, Южной Франции, Англии, Голландии и Германии [8].

Анемона корончатая (Anemone coronaria L.) - прекрасная срезочная культура. Продолжительный период цветения, высокая декоративность, разнообразие окрасок, длительное сохранение срезанных цветов создают для этой культуры хорошие перспективы [13]. Её можно выращивать как в открытом, так и в закрытом грунте для срезки, а также использовать в озеленении $[17,18]$. Получение цветочной продукции Anemone coronaria возможно при относительно невысоких температуpax, как и её выгонка к определённым датам. Хорошо идёт в культурооборотах, как цветочных, так и овощных видов $[3,5,6]$.

Анемона нежная (Anemone blanda) - это многолетнее травянистое растение. Данный вид анемоны образует прикорневую розетку из тёмно-зелёных листьев, листовая пластинка почти не имеет опушения. Цветонос опушён по всей длине, высотой 7-15 см, возвышается над розеточными листьями. Лепестки околоцветника узкие, 12-15 шт. Окраска цветков анемоны нежной - синяя, розовато-лиловая, розовая или белая. У этого вида анемоны имеются запасающие клубни [16]. Анемону нежную можно использовать в качестве горшечной культуры, а также в озеленении - как почвопокровное растение. Anemone blanda высаживают между травянистыми многолетниками, кустарниками при создании групп, также вид можно использовать при создании рокариев $[7,14,18]$.

Анемона хубейская (Anemone hupehensis) - впервые была найдена в Китае в 1908 г. в провинции Хубей. Позднее была завезена в Японию, где можно было встретить как возделываемые (культурные формы), так и её одичалых сородичей. В Европу растение привезли из Японии в окультуренном виде, поэтому оно получило название - Anemone hupehensis var. 
Глава 2. Интродукция и сортоизучение

japonica (Thunb.) Bowles \& Stearn. Растения анемоны начали выращивать в Европе с 1844 г. Цветки привезённых растений имели пурпурную окраску. В результате селекции с Anemone vitifolia Buch.-Ham. ex DC., доставленной из Неаполя в 1829 г., были получены растения с бледнорозовыми простыми цветками, которые получили название - Anemone hupehensis f. ellegans [1]. В настоящее время статус Anemone hupehensis не определен, а Anemone hupehensis var. japonica, по данным The Plant List является синонимом Anemone scabiosa H. Lev. \& Vaniot. Анемона хубейская - многолетнее растение с горизонтальными корневищными побегами, а также немногочисленными (2-4 шт.) толстыми корнями, уходящими на глубину более 30 см. Цветоносы у растений слабо опушены, средняя длина цветоноса анемоны японской - 60-100 см. В последнее время появились карликовые сорта Anemone hupehensis высотой до 20-25 см. Листья растений анемоны хубейской тройчатые с неравнозубчатыми лопастями, которые образуют прикорневую розетку. Окраска венчика кремовая, белая, розовая, пурпурная. Отдельные цветки собраны в зонтиковидные соцветия по 15-20 шт. [9, 19].

По нашим многолетним наблюдениям цветёт анемона хубейская в открытом грунте в условиях Черноморского побережья Кавказа примерно с августа по ноябрь. Этот вид анемоны используется для оформления клумб, рабаток, для создания цветочных пятен или небольших групп на газонах, для цветочного оформления садов, в групповых посадках с древесно-кустарниковой растительностью, в линейных посадках. В связи с тем, что у анемоны круглый год идёт процесс органогенеза, лучшее место для посадки под кронами листопадных деревьев. Для её развития в осенне-зимний и весенний период требуются открытые светлые участки, а в период цветения (конец лета - начало осени) - полузатенённые. Анемона хубейская пригодна для срезки и зимней выгонки [4].

Объекты и методы. Исследования проводили на сортах и гибридных формах анемоны корончатой, анемоны нежной и анемоны хубейской по Методике первичного сортоизучения цветочных культур [2] и Методике государственного сортоиспытания сельскохозяйственных культур [15]. При оценке сортов учитывали высоту цветоноса, сроки цветения, окраску и форму цветков, продолжительность цветения, способность к семенному и вегетативному размножению, устойчивость к заболеваниям и вредителям, устойчивость к неблагоприятным погодным условиям. Проводили фенологические наблюдения по основным фазам развития растения, особый акцент делался на сроки начала цветения сортов коллекции рода анемоны (Anemone L.), продолжительность цветения и дату окончания вегетации. 
Результаты и их обсуждение. В конце 70-х гг. ХХ века из Голландии институтом было получено в исследование десять сортов анемоны корончатой. После их тщательного изучения в коллекцию было передано только семь. В дальнейшем к этим семи сортам, которые по своим хозяйственно-биологическим и декоративным показателям подошли для выращивания в условиях Черноморского побережья Краснодарского края, добавился ещё один сорт. В зоне Черноморского побережья (Сочинский Госсортоучасток) было районировано 6 голландских сортов анемоны корончатой (A. coronaria): 'The Admiral', 'Lord Lieutenant', 'Hollandia', 'The Governer', 'Mr. Fokker', 'Sylphide' и один сорт анемоны нежной (A. blanda) - 'White Splendor'.

В настоящее время в коллекции Института находятся 16 сортов Anemone coronaria. Из них 8 сортов зарубежной селекции: 4 сорта группы - De Caen ('Hollandia', 'Mr. Fokker', 'Sylphide', 'The Bride') и 4 сорта группы di Santa Brigida ('The Admiral', 'Lord Lieutenant', 'The Governer', 'Mount Everest'). У сортов группы De Caen околоцветник с широкими лепестками, расположенными в один ряд. Иногда во втором ряду имеются лепестки, не замыкающие круг венчика полностью. Число лепестков в этой группе у цветка составляет от 6 до 9 шт. У сортов группы di Santa Brigida околоцветник имеет множество довольно узких лепестков, расположенных в несколько рядов.

Для пополнения коллекции новыми сортами отечественной селекции с заданными признаками, более приспособленными к условиям произрастания, были начаты исследования по выведению новых сортов анемоны корончатой. В результате селекционных исследований на базе ВНИИЦиСК получено 8 сортов анемоны корончатой: 5 сортов группы De Caen ('Cвелена', 'Красная шапочка', 'Синеглазка', 'Полина', ‘Летняя ночь') и 3 сорта группы di Santa Brigida ('Фея’, ‘Эоланта', ‘Лесной ручей’). Окраска венчика - бело-розовая, тёмно-красная, светло-синяя, бледно-жёлтая, пурпурная, насыщенно-синяя, розовая, фиолетовая, бело-зелёная [10-12].

Количество сортов в мировой коллекции анемоны хубейской в настоящее время увеличилось. Были созданы сорта, как с простым околоцветником, так и с полумахровым и даже - махровым. Сорта с высокими цветоносами - это 'Pamina', 'Max Vogel' (сорта с простым околоцветником), 'Queen Charlotte', 'Mararete', 'Alice', 'September Charm' (сорта с полумахровым и махровым околоцветником). Карликовые сорта этого вида анемоны имеют высоту цветоноса не более 20-25 см. Карликовые сорта с простым околоцветником - это 'Alba', 'Honorine Jebert', a c полумахровым - 'Princ Heinrinch', 'Whirlwind'. 
Глава 2. Интродукция и сортоизучение

В коллекции института имеется два сорта Anemone hupehensis c простым околоцветником - это 'Pamina' и 'Max Vogel', а также белая гибридная форма.

Много лет на коллекционном участке поддерживался сорт Anemone blanda - 'Rosea'. Сорт 'White Splendor', изученный в 1988 г. и районированный, впоследствии был утерян. В 2015 г. он был восстановлен. Соответственно на данный момент в коллекции ФГБНУ ВНИИЦиСК имеется два сорта анемоны нежной - 'Rosea' и 'White Splendor' (табл. 1).

Таблий 1

Представители рода Anemone в коллекции ВНИИЦиСК

\begin{tabular}{|l|l|c|c|}
\hline \multicolumn{2}{|c|}{ Anemone coronaria } & \multirow{2}{*}{$\begin{array}{c}\text { Anemone } \\
\text { hupehensis }\end{array}$} & $\begin{array}{c}\text { Anemone } \\
\text { blanda }\end{array}$ \\
\cline { 1 - 2 } зарубежные copта & \multicolumn{1}{|c|}{$\begin{array}{c}\text { отечественные } \\
\text { сорта }\end{array}$} & 'Pamina' & 'White Splendor' \\
\hline 'Lord Lieutenant' & 'Свелена' & 'Rosea' \\
\hline 'Mr. Fokker' & 'Феся' & $\begin{array}{c}\text { Гибр. форма } \\
\text { (белая) }\end{array}$ & \\
\hline 'Hollandia' & 'Синеглазка' & & \\
\hline 'The Admiral' & 'Полина' & & \\
\hline 'Mount Everest' & 'Летняя ночь' & & \\
\hline 'Sylphide' & 'Лесной ручей' & & \\
\hline 'The Bride' & 'Эоланта' & & \\
\hline
\end{tabular}

Посадка анемоны корончатой в условиях влажных субтропиков Черноморского побережья России проводится осенью (октябрь-ноябрь). Оптимальные сроки посадки в открытом грунте 15 октября - 15 ноября. При данном сроке посадки растения успевают сформировать листовые розетки в ноябре - декабре. За счёт осенней посадки бутонизация у данного вида анемоны начинается в конце февраля - начале марта, а цветение отмечается во второй половине марта.

Продолжительность цветения сортов анемоны корончатой - 5168 дней (7-9 недель). В среднем продолжительность цветения составляет - 57 дней (8 недель). Окончание вегетации данного вида фиксируется в первой декаде июня.

Посадка Anemone blanda в условиях Черноморского побережья проводится осенью в те же сроки, что и посадка анемоны корончатой. От высадки анемоны нежной в грунт до всходов проходит от трёх до четырёх месяцев. Всходы у этого вида анемоны появляются в первой половине марта (табл. 2). 
Наступление фенологических фаз у сортов рода Anemone

\begin{tabular}{|c|c|c|c|c|c|}
\hline \multirow{2}{*}{ Сорт, гибрид } & \multirow{2}{*}{$\begin{array}{c}\text { Массовые } \\
\text { всходы }\end{array}$} & \multicolumn{2}{|c|}{ Цветение } & \multirow{2}{*}{$\begin{array}{c}\text { Продолж. } \\
\text { цветения, } \\
\text { дни }\end{array}$} & \multirow{2}{*}{$\begin{array}{c}\text { Оконча- } \\
\text { ние веге- } \\
\text { тации }\end{array}$} \\
\hline & & начало & массовое & & \\
\hline \multicolumn{6}{|c|}{ Anemone coronaria } \\
\hline 'Lord Lieutenant' & 30.11 & 05.04 & 15.04 & 55 & 10.06 \\
\hline 'The Governor' & 26.11 & 05.04 & 15.04 & 54 & 07.06 \\
\hline 'Mr. Fokker' & 30.11 & 05.04 & 15.04 & 52 & 10.06 \\
\hline 'Hollandia' & 30.11 & 05.04 & 15.04 & 52 & 07.06 \\
\hline 'The Admiral' & 26.11 & 27.03 & 05.04 & 59 & 07.06 \\
\hline 'Mount Everest' & 26.11 & 01.04 & 08.04 & 57 & 10.06 \\
\hline 'Sylphide' & 30.11 & 01.04 & 15.04 & 59 & 10.06 \\
\hline 'The Bride' & 26.11 & 29.03 & 08.04 & 59 & 07.06 \\
\hline ‘Свелена' & 26.11 & 01.04 & 12.04 & 59 & 10.06 \\
\hline 'Красная Шапочка' & 03.12 & 09.04 & 17.04 & 51 & 10.06 \\
\hline ‘Фея’ & 25.11 & 25.03 & 15.04 & 61 & 12.06 \\
\hline ‘Синеглазка' & 27.11 & 01.04 & 20.04 & 55 & 05.06 \\
\hline ‘Полина' & 24.11 & 18.03 & 15.04 & 68 & 07.06 \\
\hline ‘Летняя ночь' & 01.12 & 10.04 & 25.04 & 52 & 10.06 \\
\hline ‘Лесной ручей’ & 27.11 & 27.03 & 20.04 & 58 & 07.06 \\
\hline ‘Эоланта’ & 30.11 & 16.03 & 25.04 & 66 & 10.06 \\
\hline \multicolumn{6}{|c|}{ Anemone hupehensis } \\
\hline 'Pamina' & 20.02 & 18.08 & 05.10 & 89 & 01.12 \\
\hline 'Max Vogel' & 15.02 & 27.07 & 25.08 & 85 & 10.12 \\
\hline $\begin{array}{l}\text { Гибридная форма } \\
\text { (белая) }\end{array}$ & 23.02 & 25.08 & 31.09 & 95 & 10.12 \\
\hline \multicolumn{6}{|c|}{ Anemone blanda } \\
\hline 'White Splendor' & 14.03 & 17.03 & 22.03 & 38 & 18.05 \\
\hline 'Rosea' & 10.03 & 16.03 & 24.03 & 37 & 15.05 \\
\hline
\end{tabular}


Глава 2. Интродукция и сортоизучение

Бутоны у сорта 'White Splendor' появляются раньше листовой розетки, а у сорта 'Rosea' - немного позже, но очень быстро, от появления всходов до цветения проходит 5-7 дней. Массовое цветение этого вида приходится на конец марта - начало апреля. При массовом цветении анемоны нежной посадки выглядят как живописный красочный ковёр. Продолжительность цветения Anemone blanda в районе города Сочи в отдельные годы отмечалась до 45 дней. Средняя продолжительность цветения для сортов этого вида анемоны - 37 дней.

В условиях влажных субтропиков Черноморского побережья по окончании вегетации клубни Anemone blanda желательно выкапывать, так как есть высокая вероятность появления различных заболеваний клубней в летний период.

Сорта анемоны хубейской во влажных субтропиках России заканчивают вегетацию в первой декаде декабря, а появление новых листьев на зимующих розетках отмечается уже с середины февраля. Ежегодно первое цветение фиксируется на сорте 'Max Vogel' в конце июля, затем - на сорте 'Раmina'. Немного позже зацветает белая гибридная форма. Продолжительность цветения сортовых растений - 70-90 дней (10-12 недель). Гибридная форма отличается более продолжительным цветением, в отдельные годы - до середины декабря.

В результате исследований было установлено, что закладку посадок Anemone hupehensis необходимо проводить с третьей декады марта до середины апреля. Посадочный материал должен быть с закрытой корневой системой. На одном месте растения Anemone hupehensis могут выращиваться до 6-8 лет. Схема посадки: $40 \times 40$ см.

Во время проведения исследований сортов анемоны были получены биометрические параметры коллекционного материала, находящегося в закрытом грунте (неотапливаемая теплица) и получающих полив весь сезон вегетации (табл. 3).

Габитус листовой розетки сортов анемоны корончатой в открытом грунте в среднем составляет $21,4 \times 13,9$ см. Самая компактная розетка листьев - у сорта 'The Bride' $(15,1 \times 10,4$ cм), а самая крупная - у отечественного сорта 'Полина' $(24,7 \times 15,5$ см). Селекция новых сортов была сориентирована на получение цветочной продукции с более крупным цветоносом и цветком, поэтому средний диаметр цветка отечественных сортов составляет 8,5 cм, средняя высота цветоноса - 34,6 см, тогда как средний диаметр цветка зарубежных сортов - 6,5 см, а средняя высота цветоноса - 24,6 см. 
Биометрические показатели сортов рода Anemone

\begin{tabular}{|c|c|c|c|c|c|}
\hline \multirow{2}{*}{ Сорт, гибрид } & \multicolumn{2}{|c|}{ Габитус растения } & \multirow{2}{*}{$\begin{array}{c}\text { Диаметр } \\
\text { цветка, } \\
\text { см }\end{array}$} & \multirow{2}{*}{$\begin{array}{c}\text { Длина } \\
\text { цвето- } \\
\text { носа, } \\
\text { см }\end{array}$} & \multirow{2}{*}{$\begin{array}{c}\text { Кол-во } \\
\text { цветков } \\
\text { на } 1 \text { растении, } \\
\text { штm. }\end{array}$} \\
\hline & $\begin{array}{c}\text { диаметр, } \\
c м\end{array}$ & $\begin{array}{l}\text { высота, } \\
\text { см }\end{array}$ & & & \\
\hline \multicolumn{6}{|c|}{ Anemone coronaria } \\
\hline 'Lord Lieutenant' & 23,0 & 16,0 & 6,8 & 28,5 & $7-11$ \\
\hline 'The Governor' & 18,9 & 13,0 & 7,0 & 29,0 & $8-12$ \\
\hline 'Mr. Fokker' & 21,2 & 13,5 & 6,9 & 28,5 & $8-10$ \\
\hline 'Hollandia' & 21,0 & 14,5 & 6,5 & 25,5 & $8-10$ \\
\hline 'The Admiral' & 20,0 & 13,0 & 6,3 & 22,5 & $10-12$ \\
\hline 'Mount Everest' & 20,3 & 12,6 & 6,0 & 19,0 & $10-14$ \\
\hline 'Sylphide' & 21,6 & 16,3 & 6,5 & 23,5 & $10-14$ \\
\hline 'The Bride' & 15,1 & 10,4 & 5,8 & 20,0 & $10-12$ \\
\hline ‘Свелена' & 19,1 & 12,5 & 7,8 & 30,5 & $10-12$ \\
\hline 'Красная Шапочка' & 21,5 & 12,0 & 7,4 & 28,5 & $7-11$ \\
\hline 'Фея’' & 24,4 & 15,4 & 9,2 & 39,5 & $12-14$ \\
\hline 'Синеглазка' & 22,9 & 14,8 & 8,9 & 30,2 & $10-12$ \\
\hline 'Полина' & 24,7 & 15,5 & 8,9 & 47,2 & $11-13$ \\
\hline 'Летняя ночь' & 24,7 & 14,9 & 10,1 & 38,2 & $8-10$ \\
\hline ‘Лесной ручей' & 20,9 & 13,1 & 8,0 & 32,3 & $9-11$ \\
\hline ‘Эоланта' & 22,7 & 15,3 & 7,8 & 30,5 & $10-12$ \\
\hline \multicolumn{6}{|c|}{ Anemone hupehensis } \\
\hline 'Pamina' & 55,0 & 40,0 & 5,5 & 90,0 & $50-80$ \\
\hline 'Max Vogel' & 80,0 & 50,0 & 6,0 & 120,0 & $90-120$ \\
\hline $\begin{array}{l}\text { Гибридная форма } \\
\text { (белая) }\end{array}$ & 65,0 & 45,0 & 5,8 & 105,0 & $100-140$ \\
\hline \multicolumn{6}{|c|}{ Anemone blanda } \\
\hline 'White Splendor' & 19,0 & 11,0 & 5,0 & 15,5 & $7-12$ \\
\hline 'Rosea' & 20,5 & 5,5 & 3,5 & 10,0 & $5-8$ \\
\hline
\end{tabular}

Анемона нежная - небольшое, компактное растение. Габитус листовой розетки в 2-3 раза меньше, чем у анемоны корончатой. Розеточные листья сорта 'White Splendor' крупнее, но приподняты над землёй, а листья сорта 'Rosea' меньше, прижаты к земле. Диаметр цветка, как и высота цветоносов больше у сорта 'White Splendor', а вот количество цветоносов больше у сорта 'Rosea' . 
Глава 2. Интродукция и сортоизучение

Анемона хубейская в условиях Черноморского побережья Кавказа может сформироваться в довольно крупное растение. Лимитирующими факторами в данном случае являются - наличие влаги в почве в весенне-летний период и притенки растений в летний период. На открытых сухих участках габитус Anemone hupehensis будет в два раза меньше, чем у растений, находящихся в полутени и получающих дополнительный полив. Наибольшим габитусом растений по многолетним данным отличается сорт 'Max Vogel'. У анемоны японской на одном цветоносе может насчитываться до 20 штук цветков, которые собраны в зонтиковидные соцветия. Цветоносов на одном растении обычно имеется от семи до двенадцати штук. Одновременно цветущих цветков на одном цветоносе - 2-3 шт. Диаметр цветков Aneтопе hupehensis небольшой - 4-7 см, наибольший у сорта 'Max Vogel'.

\section{Заключение:}

1. В настоящее время в коллекции Института содержатся 16 сортов Anemone coronaria, том числе 8 зарубежной селекции: 'Hollandia', 'Mr. Fokker', 'Sylphide', 'The Bride', 'The Admiral', 'Lord Lieutenant', 'The Governer', 'Mount Everest' и 8 отечественной селекции: 'Свелена', 'Красная шапочка', 'Синеглазка', 'Полина', ‘Летняя ночь', ‘Фея’, ‘Эоланта', 'Лесной ручей'. Два сорта Anemone blanda - 'Rosea' и 'White Splendor', а также сорта Anemone hupehensis - 'Pamina' и 'Max Vogel', а также белая гибридная форма.

2. Продолжительность цветения сортов Anemone coronaria - 51-68 дней (7-9 недель). В среднем продолжительность цветения составляет 57 дней (8 недель). Продолжительность цветения Anemone blanda в отдельные годы достигает 45 дней, средняя продолжительность цветения - 37 дней; соответственно, Anemone hupehensis - 70-90 дней (10-12 недель).

3. Сорта Anemone coronaria отечественной селекции отличаются как большей величиной цветка, так и длиной цветоноса. Габитус листовой розетки сортов анемоны корончатой в открытом грунте в среднем составляет $21,4 \times 13,9$ см. Самая компактная розетка листьев - у 'The Bride' $(15,1 \times 10,4$ cм $)$, а самая крупная - у отечественного сорта 'Полина' $(24,7 \times 15,5$ см). Габитус растений Anemone hupehensis и количество цветков зависит от условий произрастания и насыщенности почвы влагой в период вегетации. Наибольшим габитусом растений по многолетним данным отличается сорт 'Max Vogel'. Габитус листовой розетки Anemone blanda в 2-3 раза меньше, чем у A. coronaria. Розеточные листья 'White Splendor' крупнее, но приподняты над землёй, а листья 'Rosea' меньше, прижаты к земле. Диаметр цветка, высота цветоносов больше у 'White Splendor', а вот количество цветоносов больше у 'Rosea'. 


\section{Библиографический список}

1. Благовидова М.С., Зайцева Е.Н., Краснова Н.С. Декоративные многолетники. - М., 1960. - С. 274-276.

2. Болгов В.И., Евсюкова Т.В., Козина В.В., Пустынников М.А. Методика первичного сортоизучения цветочных культур. - М., 1998. - С. 33-39.

3. Болгов В.И., Мохно В.С., Евсюкова Т.В., Братухина Е.В., Козина В.В., Козина С.В., Слепченко Н.А. Выгонка луковичных и клубнелуковичных цветочных культур / под ред. В.И. Болгова. - Сочи, 2001. - 96 с.

4. Декоративные многолетники (краткие итоги интродукции). - М.: Изд-во АН СССР, 1960. - C. $45-49$

5. Евтюхова М.А. Дикорастущие весенние цветы для садов и парков / под ред. акад. Н.В. Цицина. - М.: Наука, 1968. - 127 с.

6. Козина В.В., Клемешова К.В. Анемона корончатая - срезочная культура, использование во флористике // Субтропическое и декоративное садоводство. - 2017. Вып. 62. - C. 172-178. - ISSN: 2225-3068.

7. Козина В.В., Козина С.В. Анемона нежная на Черноморском побережье Краснодарского края // Субтропическое и декоративное садоводство. - 2017. - Вып. 63. C. 44-49. - ISSN: 2225-3068.

8. Козина В.В., Козина С.В. Ветреница // Субтропическое и декоративное садоводство. - 2004. - Вып. 39. - С. 163-170. - ISSN: 2225-3068.

9. Козина С.В., Козина В.В. Анемона японская в условиях влажных субтропиков России // Субтропическое и декоративное садоводство. - 2013. - Вып. 49. - С. 95-101. - ISSN: 2225-3068.

10. Козина С.В. Создание сортов анемоны корончатой на Черноморском побережье Краснодарского края // Субтропическое и декоративное садоводство. - 2015. - Вып. 55. - С. 87-92. - ISSN: 2225-3068.

11. Козина С.В. Сорта и перспективные гибриды анемоны корончатой // Вестник Российской академии сельскохозяйственных наук. - № 6. - 2015. - С. 51-53. - ISSN: 2500-2082.

12. Козина С.В. Результаты селекционных исследований. Анемона корончатая // Субтропическое и декоративное садоводство. - 2016. - Вып. 59. - С. 81-85. - ISSN: 2225-3068.

13. Кравцов И.А., Евсюкова Т.В., Козина В.В., Слепченко Н.А. Рекомендации по оценке качества цветочной продукции (гипсофила метельчатая, анемона корончатая, белоцветник летний). - Сочи, 2009. - 21 с.

14. Маркова-Щеброва И. Многолетники: декоративные, полезные, вкусные // Цветоводство. - 2006. - № 4. - С. 50-53. - ISSN: 0041-4905.

15. Методика государственного сортоиспытания сельскохозяйственных культур. Вып. 6 (декоративные культуры). - М.: Колос, 1968. - 224 с.

16. Пупова Л.Н. Ранневесенние декоративные растения в условиях Крыма: автореф. дис. ... канд. с.-х. наук. - Л., 1975. - 24 с.

17. Рындин А.В., Келина А.В., Клемешова К.В. Использование многолетних цветочных культур в зоне влажных субтропиков России // Субтропическое и декоративное садоводство. - 2014. - Вып. 50. - С. 13-20. - ISSN: 2225-3068.

18. Рындин А.В., Келина А.В., Слепченко Н.А., Клемешова К.В. Перспективы импортозамещения в декоративном садоводстве субтропической зоны России // Субтропическое и декоративное садоводство. - 2015. - Вып. 55. - С. 19-26. - ISSN: 2225-3068. 19. Справочник цветовода / под ред. А.Т. Федорука. - Минск: Уроджай, 1984. - 20 с.

\section{ANEMONE L. COLLECTION IN THE CONDITIONS OF HUMID SUBTROPICS}

Kozina V. V., Kozina S. V. 
Глава 2. Интродукция и сортоизучение

\author{
Federal State Budgetary Scientific Institution \\ "Russian Research Institute of Floriculture and Subtropical Crops", \\ c. Sochi, Russia, e-mail: tsvetovodstvo@vniisubtrop.ru
}

The genus Anemone L. belongs to the buttercup family (Ranunculaceae L.). There are three species on the collection section of the FSBSI "Russian Research Institute of Floriculture and Subtropical Crops": Anemone coronaria, Anemone blanda and Anemone hupehensis. Currently, the collection of the Institute contains sixteen cultivars of the poppy anemone, two cultivars of Japanese anemone - 'Pamina' and 'Max Vogel', and a white hybrid form, as well as two cultivars of Balkan anemone - 'Rosea' and 'White Splendor'. The flowering time of A. coronaria cultivars is 51-68 days, A. blanda - up to 45, A. hupehensis - 70-90 days (10-12 weeks). The average diameter of the flower of A. coronaria domestic cultivars is $8.5 \mathrm{~cm}$, the average height of the peduncle is $34.6 \mathrm{~cm}$, while the average flower diameter of foreign cultivars is $6.5 \mathrm{~cm}$ and the average height of the peduncle is $24.6 \mathrm{~cm}$. The diameter of the flower of 'White Splendor' cultivar is $5.0 \mathrm{~cm}$ and the height of the peduncles is $15.5 \mathrm{~cm}$. One plant of A. hupehensis usually has from seven to twelve peduncles, their height reaches $120 \mathrm{~cm}$. There are 2-3 simultaneously blossoming flowers on one peduncle. The diameter of $A$. hupehensis flowers is $4-7 \mathrm{~cm}$.

Key words: Anemone, collection, genus, cultivar, growing conditions.

УДК 633.72:631.5

doi: 10.31360/2225-3068-2018-66-57-61

\title{
COРТА И ФОРМЫ CAMELLIA SINENSIS (L.) KUNTZE В КОЛЛЕКЦИИ ГОЙТХСКОГО ФИЛИАЛА ВНИИЦИСК
}

\author{
Коннов Н. А.
}

Гойтхский филиал

Федерального государственного бюджетного научного учреждения «Всероссийский научно-исследовательский институт цвветоводства и субтропических культур», c. Шаумян, Туапсинский район, Россия, e-mail: konnov_n_a@bk.ru

В статье рассмотрена история, современное состояние и перспективы культивирования Camellia sinensis (L.) Kuntze за пределами субтропической зоны Черноморского побережья России. Приведён перечень сортов и форм, культивируемых в предгорьях Туапсинского района, выдвинуто мнение о формировании обособленной сорт-популяции. Дана оценка разнообразия и ценности объектов из коллекции Гойтхского филиала Всероссийского научноисследовательского института цветоводства и субтропических культур. Установлены приоритетные направления дальнейших исследований и перспектив промышленного чаеводства за пределами зоны влажных субтропиков России.

Ключевые слова: Camellia sinensis, чаеводство, коллекция, селекция, сортапопуляции. 